\title{
Reductions in HIV Stigma as Measured by Social Distance: Impact of a Stigma Reduction Campaign in a Historically Black University
}

\author{
Emily Locke ${ }^{1}$, Angela Meshack ${ }^{2}$, Ruth Githumbi ${ }^{3}$, Glenn Urbach ${ }^{3}$, Beau Miller ${ }^{3}$, Ron Peters ${ }^{1}$, and Michael W. Ross ${ }^{1}$ \\ ${ }^{1}$ Center for Health Promotion and Prevention Research, School of Public Health, University of Texas, PO Box 20126, \\ Houston TX 77225, USA \\ ${ }^{2}$ College of Pharmacy and Health Sciences, Texas Southern University, 3100 Cleburne, Houston TX 77004. \\ ${ }^{3}$ LIVE Consortium, 1521 Branard, Houston, TX 77006. \\ Correspondence: Dr Michael Ross, Center for Health Promotion and Prevention Research, School of Public Health, \\ University of Texas, PO Box 20126, Houston TX 77225, USA.
}

\author{
Received: April 11, 2014 \\ Accepted: April 25, 2014 \\ Available online: July 4, 2014 \\ doi:10.11114/ijsss.v2i3.458 \\ URL: http://dx.doi.org/10.11114/ijsss.v2i3.458
}

\begin{abstract}
We evaluated the effectiveness of a small media campaign intervention on a historically African American college campus aimed to lower social distance (willingness to interact) for people with HIV. A modified version of the Bogardus Social scale was used to measure social distance. The survey included questions regarding HIV transmission knowledge and sympathy felt towards those with HIV. Time between pre-test $(n=207)$ and post-test $(n=210)$ was 1 month. There was significant change in social distance from pre- to post-test only among women $(\mathrm{p}<.001)$. In a regression analysis transmission knowledge ( $\mathrm{p}=.027)$, sympathy towards those with HIV $(\mathrm{p}=.000)$ and gender $(\mathrm{p}=.000)$ were significantly related to social distance. There was a significance difference between men and women for transmission knowledge $(\mathrm{p}=.001)$ and sympathy $(\mathrm{p}=.001)$. Small media campaigns can be effective at lowering social distance among female African American students but may need to be modified to be effective among males.
\end{abstract}

\section{Introduction}

The issue of stigma and discrimination surrounding HIV/AIDS is one of the most difficult HIV barriers to address, but is an essential consideration to end the spread of the disease, and to ensure those living with the disease can live more healthy and full lives (Vanable, Carey, Blair, \& Littlewood, 2006; Treisman \& Angelino, 2004; Mann, 1987). HIV-related stigma has been found to lead to avoiding HIV testing (Eisenman, Cunningham, Zierler, Nakazono, \& Shapiro, 2003; Fortenberry et al., 2002; Galvan, Bing, \& Bluthenthal, 2000). Galvan et al. found in a survey among high-risk individuals in the U.S. that the 3 most common reasons for not getting HIV tested included: the fear of finding out they are positive (25\%), belief that it is unlikely they have been exposed to HIV (18\%), and the belief that they are HIV negative (13\%). Other barriers given included the fear of stigma and discrimination if positive and the concerns surrounding privacy of HIV status (2000).

Recently, the CDC reported that one-fourth of new HIV infections are among U.S. youth and young adults (13 to 24 years of age). Yet, in a national health survey given to $18-24$ year olds, only $35 \%$ reported to have been tested for HIV (CDC, 2012). Since HIV infection rate among African Americans in the U.S. is highest of all ethnic groups, it reasonable to assume that on predominantly African American college campuses there will be a higher number of students living with HIV and who have been personally affected (know someone who is infected) by the disease, and a significant proportion who are untested. Hightow et al. (2005) in fact found that there are increasing rates of HIV infections among African American men attending college. The CDC (2008) reports that $21 \%$ of HIV infections in the African American population are undetected, and $31 \%$ of African Americans have never been tested for HIV.

Among college students in the U.S., students feel that there is personal responsibility related to transmission of the disease, that fear of HIV/AIDS is a predictor of stigma and social distance to those that are HIV positive, and that HIV-related stigma and attributions of blame are largely associated with homosexuality and IV drug abuse (Henschel, 1999). Research also indicates that among college students who have more favorable attitudes towards those with HIV, there is a positive correlation with knowledge of HIV transmission and having a lower fear of being infected by HIV (Thompson, Geher, Stevens, Stem \& Lintz, 2001; Handler, Lampman, Levy, \& Weeks, 1994). Females tend to have a greater knowledge about HIV transmission and to be more tolerant of those with HIV compared to males (Lindley, 
Coleman, Gaddist, \& White, 2010; Chng, Carlon, \& Toynes, 2006; Handler, Lampman, Levy, \& Weeks, 1994). Although overall adolescents and college students seem to have high levels of accurate knowledge of transmission, there are still apparent gaps in knowledge and common misconceptions (Inungu, Mumford, Younis \& Langford, 2009). The purpose of this study was to evaluate the effectiveness of a small media, anti-stigma against HIV campaign on a predominantly African American college campus. Such information will help to determine if a small media campaign can be a feasible way to reduce HIV-related stigma among African American college students. This study will also identify if there are any variables directly related to stigma, as such information could be used to improve programming to address this issue of HIV-related stigma.

\section{Methods}

This study was conducted to evaluate a small media campaign developed by a non-profit organization, LIVE Consortium, which aims to lower stigma regarding the issues of HIV and reduce social distance towards those that are HIV positive. The campaign was modified to meet the needs of the students on a historically African American university in the Southern region of the United States. These needs were determined by running a small focus group with 9 students in the Health Sciences department on campus.

\subsection{The Intervention}

In student focus groups before the campaign, students were asked questions regarding the topic of HIV/AIDS and how stigma of disease exists on campus. The students stated that, "HIV is on their radar, but there is a need to address the issue of misconceptions about transmission and the type of people who become infected". They also informed the planning team the areas of campus with the heaviest foot traffic to hang up or hand out campaign material and the best modes to spread anti-stigma messages. The campaign took place in Fall of 2012 and consisted of: a month long HIV and stigma education small media campaign consisting of posters and fliers distributed by student volunteers; biweekly newspaper advisements; and Anti-Stigma Day, a day proclaimed by the Houston City Council, which included a 200 t-shirt giveaway, HIV-content music, on-site HIV testing, and a lunchtime lecture on stigma and HIV. Water bottles and t-shirts with the LIVE logo and "Stigma stops with you. Know about it, think about it, talk about it" were given in return for the student filling out pre- and post-surveys. Posters and fliers were hung and handed out across campus with two different HIV and stigma-related messages each week Figure 1). For the four weeks of the campaign, there was a focus on a particular aspect of the problem, starting with the problem of HIV stigma, what it means to you, what can be done about it, and "Take action": what are possible solutions to address the issue. Posters are shown on the LIVE website: www.liveconsortium.org.
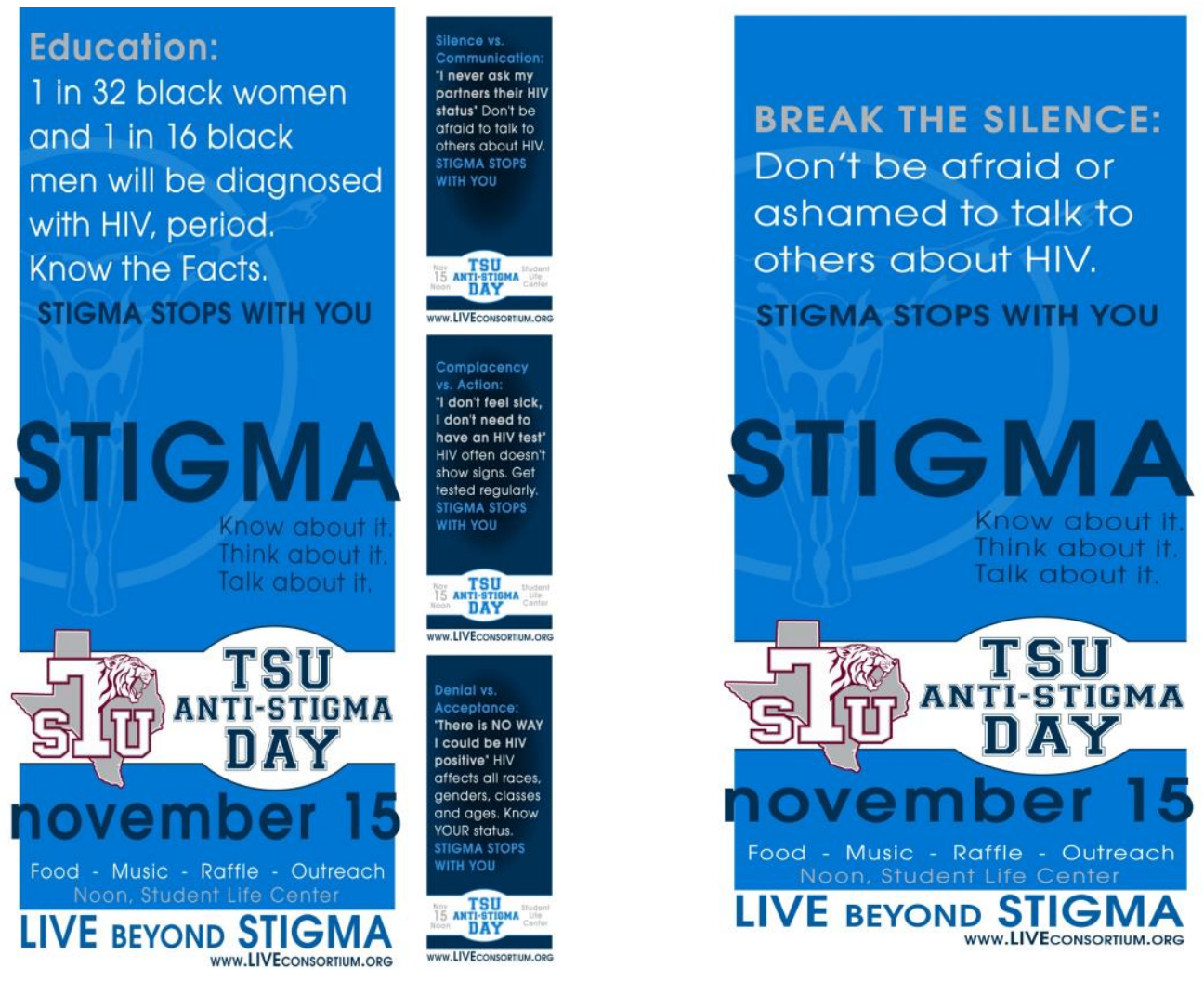

Figure 1. Example of Small media (Poster) 


\subsection{Participants and Procedure}

Individuals were recruited to voluntarily complete an anonymous questionnaire concerning their knowledge, attitudes and beliefs surrounding HIV in general and people with HIV. Pre-test surveys were distributed to students on campus and classes held in the Health Sciences department a week prior to the start of the campaign. There were in total 207 pre-test surveys filled out. Post-test surveys were then distributed at the end of campaign event (Anti-Stigma Day) held on campus plus given to students in some of the same classes the pre-surveys were given out at the start of the 30-day campaign. There were then 210 post surveys filled out (See in Table 1). The survey took about 5 minutes maximum to complete.

Table 1. Number of Surveys Administrated

\begin{tabular}{llll}
\hline Location of Survey & On-campus & In-class & Total \\
\hline Pre-Surveys $(N)$ & 43 & 164 & 207 \\
\hline Post-Survey $(N)$ & 120 & 90 & 210 \\
\hline
\end{tabular}

Subjects were given a written statement regarding the research goals and advised that information would be kept confidential. By signing the consent page, the participants gave consent to voluntarily participate in this research. The consent page was detached from the survey immediately after turning in survey. The project protocol was approved by the Institutional Review Board of the sponsoring institution prior to the administration of the surveys.

\subsection{Instrument and Measures}

To conduct this assessment, the project team modified a brief survey designed to measure HIV transmission knowledge, sympathy towards those with HIV, how much the individual is personally affected by HIV and degree of stigma felt towards those with HIV. The instrument was previously used in a similar study of a campus in the same city (Millimet, Miller, Ross, Samson \& Churi, 2013). The instrument used to measure stigma was derived from the Bogardus scale which was modified to measure social distance towards people with HIV. The Bogardus scale is a scale originally developed in 1933 to measure people's willingness to engage socially with different members of diverse racial and ethnic groups, and developed for HIV by Hunter and Ross (1991). It was further slightly modified to include situations that were common for university students in the U.S. The modified scale includes 14 questions regarding different social encounters with those with HIV using a 7-point Likert scale with 1 being not willing at all, 4 being maybe and 7 being very willing. The demographic information, including age, gender, race, and college major, was also gathered from participants. Transmission knowledge was measured by correctly answering various statements about ways to contract HIV with the options of "yes", "no" and "don't know" which was counted as a wrong answer. Sympathy towards those with HIV was also measured on a 7-point Likert scale with 1 being not at all and 7 being very much.. The data was analyzed using SPSSx (version 20). A bivariate analysis was performed ( $t$-test for binary variables, and Pearson correlation coefficient for continuous variables) using pre- and post-test scores as independent variables, and then a multiple regression analysis to ascertain the multivariate contribution of these variables (gender, knowledge, number of family/friends with HIV known, sympathy for people with HIV) plus pre/post-test and data collection site (class/event) to social distance.

\section{Results}

Demographics data appear in Table 1. All participants were students at the university, with a mean age of 22 years. Since the campus is a historically black college campus, all respondents of the survey identified themselves as African American or African. The students' majors were asked and then broken into 6 groups by college. Pre-and post-differences for HIV/AIDS transmission knowledge, social distance, and sympathy for people with HIV appear in Table 3. Pre-and post-test differences were significant for social distance only among women, indicating an increase in willingness among women to engage in social situations with someone who is HIV positive after the intervention. The regression analysis examined the variables knowledge, gender, number of family or friends known with HIV, whether data collected at class or event, and pre- to post-test (which is the measure of the intervention) to social distance (See Table 4). The significant variables included: knowledge, gender, knowing family and friends with HIV, and pre- or post-test. The regression results also indicated that there was no significant difference in source of data (class or event) on the social distance measure. 
Table 2. Demographic characteristics

\begin{tabular}{llll}
\hline Gender $N$ (Percent) & Female & Male & Other \\
\hline Pre & $99(49.7 \%)$ & $100(48.8 \%)$ & $1(0.5 \%)$ \\
\hline Post & $100(50.3 \%)$ & $105(51.2 \%)$ & 0 \\
\hline \multicolumn{1}{|l}{ Age } & Mean & Median & Std. Dev. \\
\hline Pre & 20.9 & 21 & 3.5 \\
\hline Post & 23.4 & 21 & 4.3 \\
\hline & & $\mathrm{N}($ Percent $)$ \\
\hline Major & & \\
\hline Business & & $23(11.1 \%)$ \\
\hline Health-Related & & $96(46.2 \%)$ \\
\hline Science/Math & & $21(10.1 \%)$ \\
\hline Education & & $10(4.8 \%)$ \\
\hline Technology & & $10(4.8 \%)$ \\
\hline General & & $31(14.9 \%)$ \\
\hline
\end{tabular}

Table 3. Variable Differences Between Pre and Post Test

\begin{tabular}{cccccc}
\hline Variable & $\begin{array}{c}\text { Pre-test } \\
\text { Mean } \pm \text { SD }(\mathrm{n})\end{array}$ & $\begin{array}{c}\text { Post-test } \\
\text { Mean } \pm \text { SD }(\mathrm{n})\end{array}$ & t & df & p \\
\hline Social Distance $\Sigma$ & $62.23 \pm 21.92(207)$ & $65.90 \pm 21.25(209)$ & -1.73 & 414 & .04 \\
\hline Social Distance (males) & $70.13 \pm 20.79(99)$ & $69.00 \pm 21.71(99)$ & -.39 & 196 & .70 \\
\hline Social Distance (females) & $53.48 \pm 20.21(100)$ & $61.85 \pm 19.54(105)$ & -3.01 & 203 & .001 \\
\hline Knowledge & $4.55 \pm 1.15(210)$ & $4.37 \pm 1.35(207)$ & 1.46 & 415 & .15 \\
\hline Sympathy & $5.17 \pm 1.75(206)$ & $5.05 \pm 1.75(208)$ & .65 & 412 & .514 \\
\hline
\end{tabular}

Table 4. Regression on Social Distance Scores

\begin{tabular}{cccc}
\hline Variable & $\boldsymbol{\beta}$ & $\mathbf{t}$ & $\mathbf{p}$ \\
\hline Pre- or Post-test & .204 & 4.15 & .000 \\
\hline Gender & .200 & 4.25 & .000 \\
\hline Knowledge & .156 & 3.35 & .011 \\
\hline Class/Event & .018 & 0.37 & .711 \\
\hline $\begin{array}{c}\text { Number family/friends know } \\
\text { with HIV }\end{array}$ & .205 & 4.45 & .000 \\
\hline $\mathrm{R}^{2}=.185$ & & & \\
\hline
\end{tabular}

In order to examine the differences among females and males in more detail, $t$-tests were run by gender for social distance, knowledge, and sympathy (Table 5). Differences in variables between women and men were all found to be significant which included transmission knowledge, sympathy for people with HIV and social distance. In a breakdown of the questions regarding knowledge of HIV transmission, three of the six questions were found to be significantly different among females and males as seen in Table 6. The following statements answered correctly that were found to be statistically significant between females and males were "HIV can be spread by an infected mother breast-feeding her infant", "HIV can be spread from sharing eating utensils with an infected person", and "Now, HIV can be cured". The rest of the statements were found to be statistically insignificant. 
Table 5. Variable Differences Between Males and Females

\begin{tabular}{|c|c|c|c|c|c|}
\hline Variable & $\begin{array}{c}\text { Male } \\
\text { Mean } \pm \text { SD (n) }\end{array}$ & $\begin{array}{c}\text { Female } \\
\text { Mean } \pm \text { SD (n) }\end{array}$ & $\mathrm{t}$ & df & $\mathbf{p}$ \\
\hline Social Distance Pre & $70.1 \pm 20.8(100)$ & $53.3 \pm 20.2(99)$ & -5.70 & 197 & .001 \\
\hline Post & $69.0 \pm 21.7(105)$ & $61.9 \pm 19.5(99)$ & -2.46 & 202 & .015 \\
\hline Knowledge Pre & $4.33 \pm 1.23(100)$ & $4.79 \pm 1.04(99)$ & -2.83 & 197 & .005 \\
\hline Post & $4.16 \pm 1.50(105)$ & $4.63 \pm 1.13(100)$ & -2.52 & 203 & .013 \\
\hline Sympathy Pre & $4.86 \pm 1.79(100)$ & $5.45 \pm 1.71(98)$ & -2.37 & 196 & .019 \\
\hline Post & $4.78 \pm 1.86(105)$ & $5.33 \pm 1.60(99)$ & -2.27 & 202 & .024 \\
\hline
\end{tabular}

Table 6. Difference among gender of knowledge of HIV transmission

\begin{tabular}{|c|c|c|c|c|c|}
\hline Gender & Correct & Incorrect & $\begin{array}{c}\text { Pearson } \\
\text { chi-Square }\end{array}$ & df & p-value \\
\hline $\begin{array}{c}\text { Males } \\
\text { Females }\end{array}$ & $\begin{array}{l}169 \\
175\end{array}$ & $\begin{array}{l}36 \\
23\end{array}$ & 2.85 & 1 & .09 \\
\hline \multicolumn{6}{|c|}{ Statement 2. HIV can be spread from an infected person by coughing. } \\
\hline $\begin{array}{c}\text { Males } \\
\text { Females }\end{array}$ & $\begin{array}{l}161 \\
170\end{array}$ & $\begin{array}{l}44 \\
29\end{array}$ & 3.24 & 1 & .07 \\
\hline \multicolumn{6}{|c|}{ Statement 3. HIV can be spread from an infected person by unprotected anal sex. } \\
\hline $\begin{array}{c}\text { Males } \\
\text { Females }\end{array}$ & $\begin{array}{l}187 \\
188\end{array}$ & $\begin{array}{l}17 \\
10\end{array}$ & 1.74 & 1 & .19 \\
\hline \multicolumn{6}{|c|}{ Statement 4 . HIV can be spread from an infected mother breast-feeding her infant. } \\
\hline $\begin{array}{c}\text { Males } \\
\text { Females }\end{array}$ & $\begin{array}{l}130 \\
149\end{array}$ & $\begin{array}{l}75 \\
50\end{array}$ & 6.21 & 1 & .013 \\
\hline \multicolumn{6}{|c|}{ Statement 5. HIV can be spread from sharing eating utensils with an infected person. } \\
\hline $\begin{array}{c}\text { Males } \\
\text { Females }\end{array}$ & $\begin{array}{l}106 \\
122\end{array}$ & $\begin{array}{l}97 \\
74\end{array}$ & 4.10 & 1 & .043 \\
\hline \multicolumn{6}{|c|}{ Statement 5. Now, HIV can be cured. } \\
\hline $\begin{array}{c}\text { Males } \\
\text { Females }\end{array}$ & $\begin{array}{l}117 \\
133\end{array}$ & $\begin{array}{l}86 \\
65\end{array}$ & 3.88 & 1 & .049 \\
\hline
\end{tabular}

\section{Discussion}

The data, while limited by lack of a longitudinal design, indicate that there was a significant decrease in social distance comfort (likelihood of interaction) with those with HIV on a modified Bogardus social distance scale following the intervention. However, this decrease was only seen among female students. Other variables that showed a statistically significant association with social distance besides gender were knowledge of HIV transmission and sympathy felt towards those whom are HIV positive.

In analyzing the difference between males and females in regards to knowledge of HIV transmission and sympathy towards those with HIV both variables were statistically significant. Females had a higher level of knowledge regarding HIV and felt more sympathetic towards people who are HIV positive. Both of these findings are congruent with previous research findings (Lindley, Coleman, Gaddist, White, 2010; Chng, Carlon, Toynes, 2006; Handler, Lampman, Levy, Weeks, 1994). The male students seemed to have a similar level of knowledge to the female students regarding well-known ways to of spreading HIV like unprotected vaginal and anal sex. However male's knowledge fell short compared to females in statements regarding common misconceptions about HIV, which is similar to Inungu et. al's findings among college students (2009).

The limitations of the data include the lack of longitudinal design (not being able to reach all the same respondents for pre- and post-testing: the IRB did not approve use of identifiers). It is also hard to determine if the change seen in social distance (willingness to interact) with people with HIV is directly linked with the campaign or just the presence of a group people on campus openly talking about the issue of HIV. Our failure to ascertain what aspects of the campaign 
participants saw is an additional limitation since we are unable to assess dose and its relationship to response.

Despite the limitations of this campaign and evaluation, a small media campaign does seem to be a feasible and effective way to reduce social distance towards people with HIV and potentially reduce stigma regarding the disease. This evaluation also suggests that to make this type of programming more powerful in reducing stigma, the campaign should include information dismissing common misconceptions about HIV transmission and have a concept that allows students to emotionally feel sympathy towards those with HIV. Integrating these elements in this campaign could result in additional change.

\section{References}

American College Health Association. (2011). American College Health Association-National College Health Assessment II: Reference Group Executive Summary Fall 2010. Linthicum, MD: American College Health Association.

Centers for Disease Control and Prevention. (2008). Persons tested for HIV-United States, 2006. MMWR 57(31), 845-49.

Center for Disease Control and Prevention. (2012). Vital Signs: HIV Infection, Testing, and Risk Behaviors Among Youths — United States. Morbidity and Mortality Weekly Report (MMWR), 61(47), 971-976.

Chng, C., Carlon, A., \& Toynes, B. (2006). HIV on Historically Black Colleges and Universities (HBCU): A Study of Five Campuses in Texas, Oklahoma, Louisiana. College Student Journal, 40(1), 25-34.

Eisenman, D., Cunningham, W., Zierler, S., Nakazono, T., Shapiro, M. (2003). Effect of violence on utilization of services and access to care in persons with HIV. Journal of General Internal Medicine, 18, 125-127. http://dx.doi.org/10.1046/j.1525-1497.2003.20518.x

Fortenberry J., McFarlane, M., Bleakley, A., Bull, S., Fishbein, M., Grimley, D., Malotte, K., \& Stoner, B. (2002). Relationships of stigma and shame to gonorrhea and HIV screening. American Journal of Public Health, 92, 378-381. http://dx.doi.org/10.2105/AJPH.92.3.378

Handler, A., Lampman, C., Levy, S., Weeks, K. (1994). Attitudes toward people with AIDS and implications for school-based youth AIDS education. AIDS Education and Prevention, 6, 175-83.

Henschel, P. (1997). Stigma and attributions of blame toward persons with AIDS (PWAs). Dissertation Abstracts International, 57, 4783.

Hightow, L., MacDonald, P., Pilcher, C. Kaplan, A. Foust, E., Nguyen, T. \& Leone, P. (2005). The unexpected movement of the HIV epidemic in the Southeastern United States: transmission among college students. Journal of Acquired Immune Deficiency Syndrome, 38(5), 531-7. http://dx.doi.org/10.1097/01.qai.0000155037.10628.cb

Hunter, C.E., \& Ross, M.W. (1991). Determinants of health care workers' attitudes toward people with AIDS. Journal of Applied Social Psychology, 21, 947-956. http://dx.doi.org/10.1111/j.1559-1816.1991.tb00452.x

Inungu, J, Mumford, V., Younis, M., \& Langford, S. (2009). HIV Knowledge, Attitudes and Practices Among College Students in the United States. Journal of Health \& Human Services Administration, 32(3), 259-277.

Lindley, L., Coleman, J., Gaddist, B., White, J. (2010). Informing faith-based HIV/AIDS interventions: HIV-related knowledge and stigmatizing attitudes at Project F.A.I.T.H. churches in South Carolina. Public Health Reports, 125(1), 12-20.

Millimet, S.A., Miller, B., Ross, M.W., Samson, P., \& Churi, C. (2013). Results of an HIV stigma reduction intervention on a university campus. International Journal of Child and Adolescent Health, 6(3), in press.

Thompson, K., Geher, G., Stevens, K., Stem, S., Lintz, M. (2001). Psychological predictors of sexual behaviors related to AIDS transmission. Psychology Reports, 88, 51-67. http://dx.doi.org/10.2466/pr0.2001.88.1.51

Treisman, G. \& Angelino, A. (2004). The psychiatry of AIDS: A guide to diagnosis and treatment. Baltimore, MD: Johns Hopkins University Press.

Vanable, P., Carey, M., Blair, D., Littlewood, R. (2006). Impact of HIV-related stigma on heath behaviors and psychological adjustment among HIV-positive men and women. AIDS and Behavior, 10(5), 473-482. http://dx.doi.org/10.1007/s10461-006-9099-1

\section{$(\mathrm{cc}) \mathrm{BY}$}

This work is licensed under a Creative Commons Attribution 3.0 License. 